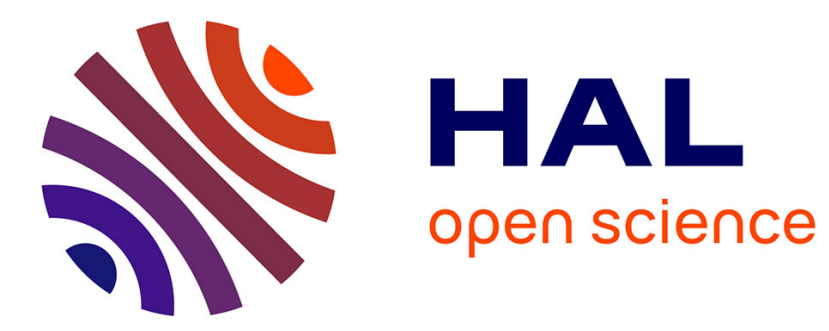

\title{
Effects of human fibronectin and human serum albumin sequential adsorption on preosteoblastic cell adhesion
}

Mathilde Hindi, Emeline Camand, Rémy Agniel, Franck Carreiras, Emmanuel Pauthe, Paul van Tassel

\section{- To cite this version:}

Mathilde Hindi, Emeline Camand, Rémy Agniel, Franck Carreiras, Emmanuel Pauthe, et al.. Effects of human fibronectin and human serum albumin sequential adsorption on preosteoblastic cell adhesion. Biointerphases, 2014, 9 (2), 10.1116/1.4867598 . hal-01926495

\section{HAL Id: hal-01926495 https://hal-cyu.archives-ouvertes.fr/hal-01926495}

Submitted on 19 Nov 2018

HAL is a multi-disciplinary open access archive for the deposit and dissemination of scientific research documents, whether they are published or not. The documents may come from teaching and research institutions in France or abroad, or from public or private research centers.
L'archive ouverte pluridisciplinaire HAL, est destinée au dépôt et à la diffusion de documents scientifiques de niveau recherche, publiés ou non, émanant des établissements d'enseignement et de recherche français ou étrangers, des laboratoires publics ou privés. 


\title{
Effects of human fibronectin and human serum albumin sequential adsorption on preosteoblastic cell adhesion
}

\author{
Mathilde Hindié, Emeline Camand, Rémy Agniel, Franck Carreiras, and Emmanuel Pauthe \\ ERRMECe, I-MAT, Université de Cergy-Pontoise, 2 Avenue Adolphe Chauvin, \\ 95302 Cergy-Pontoise Cedex, France \\ Paul Van Tassel ${ }^{\mathrm{a})}$ \\ Department of Chemical and Environmental Engineering, Yale University, New Haven, \\ Connecticut 06520-8286
}

(Received 14 January 2014; accepted 24 February 2014; published 10 March 2014)

\begin{abstract}
Fibronectin (Fn) is widely reported to promote cell adhesion and spreading, and recent reports attest to the synergistic effect of coadsorbed albumin (unexpected due to the passivating character of the latter protein). In this study, the sequential adsorption of fibronectin and albumin, and the morphology of cultured MC3T3-E1 preosteoblastic cells are investigated on three important biomaterial surfaces: silicon oxide, poly(styrene) (PS), and hydroxyapatite (HA). Using quartz crystal microgravimetry with dissipation analysis, the adsorbed protein composition and mechanics are determined. Interestingly, cell morphological changes correlate neither with the amount of Fn nor the rigidity of the protein layer. On the PS surface, Alb is seen to significantly diminish cell spreading, possibly due to Alb aggregation with a partially denatured initially placed Fn layer. HA appears to be a particularly favorable substrate for osteoblast adhesion, despite having low Fn adsorption and protein layer rigidity. (C) 2014 American Vacuum Society. [http://dx.doi.org/10.1116/1.4867598]
\end{abstract}

\section{BACKGROUND}

Controlling the cellular response is perhaps the grandest challenge of biomaterials science. Material properties, e.g., charge, hydrophobicity, mechanical rigidity, surface topography, are known to influence the cell response. In addition, proteins adsorbed to the biomaterial surface-an invariable occurrence upon exposure of the biomaterial surface to a biological fluid-are also well known to themselves influence the material-cell interaction. ${ }^{1}$

Biomaterial interactions with circulating blood components, and extracellular matrix proteins, occur immediately following implantation. ${ }^{2}$ The adsorbed proteins could act in a synergic way to confer fundamental properties to grafted materials and promote favorable interactions between host cells and the implant. ${ }^{3}$ The recruitment, retention, and conformation of adsorbed proteins depend on the intrinsic properties of the material, e.g., wettability, roughness, and charge.,

In particular, matrix proteins such as fibronectin (Fn)-a large glycoprotein composed of two subunits, each of molecular weight $250 \mathrm{kDa}$ and linked together by disulfide bondsare known to promote cell adhesion and spreading, and in biomedical applications, biomaterial-tissue integration. ${ }^{6-9}$ The structure and stability of the human plasma Fn are well known. $^{10-13}$ Nearly all cell types express and secrete Fn, where it can aggregate as fibrils with other extracellular molecules, or remain in a soluble form. ${ }^{14}$ Fn is known to modulate a number of cell behaviors, including adhesion, migration, and differentiation. ${ }^{15,16}$ It is highly enriched in blood plasma and is known to rapidly adsorb onto substrates such as

\footnotetext{
${ }^{a}$ Author to whom correspondence should be addressed; electronic mail: emmanuel.pauthe@u-cergy.fr
}

titanium oxide used for implants. Blood proteins such as albumin are generally much more concentrated in biological solution than are matrix proteins. Hence, important questions are the extent to which these blood proteins themselves adsorb to biomaterial surfaces, and their influence on the cell response. Serum albumin (Alb) is the most abundant protein in plasma, and its molecular weight is low, $65 \mathrm{kDa} .{ }^{17}$ The flexibility of the Alb structure allows it to adopt numerous conformations. ${ }^{18}$ However, in complete contrast to Fn, Alb is known for its cell antiadhesive properties. ${ }^{19}$

A number of recent papers have investigated the influence of coadsorbed layers of Fn and Alb. ${ }^{20-24}$ Sousa et al. have investigated the influence of Fn-Alb coadsorbed layers (on titania) on the adhesion and morphology of preosteoblastic MC3T3-E1 cells, and note that while cell adhesion generally correlates with extent of Fn adsorption, the Fn effect can be enhanced in the presence of a modest amount of Alb. ${ }^{21}$ Zelzer et al. considered the adhesion of fibroblasts on Fn coated plasma polymerized allylamine (ppAAm), as well as on Fn-Alb coated ppAAm via adsorption from Fn-Alb mixtures and from sequential adsorption from an Alb (or Fn) solution followed by a Fn (or Alb) solution. ${ }^{20}$ These authors also found the presence of Alb could significantly enhance the favorable influence of Fn on cell adhesion. The favorable influence of Alb - by itself a passivating protein - on the Fn-cell interaction is hypothesized to be due to interfacial crowding by Alb, resulting in Fn adsorbed in a more native conformation. $^{20}$ To test this hypothesis, and to gain further insight into the Alb-Fn effect, we report here on the formation of binary protein layers by the sequential adsorption of Fn and Alb, and their subsequent influence on the adhesion and spreading of preosteoblastic MC3T3-E1 cells derived from mouse skull bone. ${ }^{25}$ Having been well characterized in 
the literature, MC3T3-E1 cells are widely accepted as an excellent model toward understanding material-cell interactions important in bone repair. ${ }^{26-29}$

We employ quartz crystal microgravimetry with dissipation analysis (QCM-D) to determine the composition and mechanical nature of the adsorbed layers on three model biomaterial substrates [silicon oxide (SO), hydroxyapatite (HA), and polystyrene (PS)], and optical and fluorescence microscopy to evaluate the cell response. SO and PS are commonly used cell substrates, while HA is a particularly promising contemporary material for bone repair, ${ }^{30}$ offering high affinity to host hard tissue, biocompatibility, slow biodegradability in situ, and good osteoinductive capabilities. ${ }^{31}$

We find the protein adsorption and cell response to depend sensitively on the nature of the underlying material, Fn in all cases to promote cell adhesion, and, most notably, the degree of enhancement of the Fn effect by Alb to correlate strongly with the conformation and mechanical properties of the initial Fn layer.

\section{MATERIALS AND METHODS}

\section{A. Substrate characterization}

Silicon oxide (QSX 303, noted SO), polystyrene (QSX 305, noted PS), and hydroxyapatite (QSX 327, noted HA) coated quartz crystal sensors are provided by Biolin Scientific. Sensors have diameter $14 \mathrm{~mm}$, exhibit frequency $4.95 \mathrm{MHz}+/-50 \mathrm{kHz}$, and are optically polished such that surface roughness $<3 \mathrm{~nm}$. The specific surface chemistry of the HA sensors consist on a uniform nanocrystalline hydroxyapatite $\left(\mathrm{Ca}_{10}\left(\mathrm{PO}_{4}\right)_{6}(\mathrm{OH})_{2}\right)$.

The wettability of the sensor surfaces are obtained from contact angle measurements of pure deionized water using a Drope Shape Analysis DSA 10 Mk2 instrument and analysis software. The topography of the SO, PS, and HA substrates are measured using tapping mode atomic force microscopy (AFM) (Nanoscope IIIa, Digital Instruments) under ambient conditions. For each substrate, several samples are examined at three random spots each.

\section{B. Protein coating}

Protein coatings on all surfaces are carried out with Fn purified from human blood plasma in our laboratory ${ }^{32}$ and subsequently with human serum albumin (Alb; SigmaAldrich, Saint Louis, MO, A-9511). Substrates are coated with $200 \mu \mathrm{L}$ of a $50 \mu \mathrm{g} / \mathrm{mL}$ Fn solution for $30 \mathrm{~min}$ and then washed three times with phosphate-buffered saline (PBS) $1 \times p \mathrm{H}$ 7.4. The substrates are subsequently coated with a $1 \%(\mathrm{w} / \mathrm{v})$ Alb solution in PBS1X for an additional $30 \mathrm{~h}$ and washed three times with PBS1X.

\section{Quartz crystal microgravimetry with dissipation}

The QCM apparatus consists of a thin quartz disc sandwiched between a pair of electrodes. The resonant frequency of the crystal, when excited by an alternating current voltage, depends on the total oscillating mass, including coupled water. The dissipation (D), or damping, of the crystal's oscillation reveals the softness of the film (viscoelasticity) and is defined as $\mathrm{D}=\mathrm{E}_{\text {lost }} / 2 \pi \mathrm{E}_{\text {stored }}$, where $\mathrm{E}_{\text {lost }}$ is the energy lost (dissipated) during one oscillation cycle and $\mathrm{E}_{\text {stored }}$ is the total energy stored in the oscillator. A soft adsorbed layer exerting strong damping leads to a large $\mathrm{D}$, so the change in dissipation $(\Delta \mathrm{D})$ is related to a change in the rheological properties (or softness) of the adsorbed protein layer.

The QCM-D instrument (D300, Q-Sense, Sweden) is composed of a parallel plate flow cell whose bottom surface is a Sensor Chip (Q-Sense), consisting of a planar SO, PS, or HA layer on a quartz crystal. SO, PS, and HA-coated sensor chips are placed in the flow cell and thoroughly rinsed with PBS until a stable baseline is achieved. The equilibrated sample solution is introduced into a chamber (volume $75 \mu \mathrm{l}$ ) in contact with the sensor (area $0.78 \mathrm{~cm}^{2}$ ), detecting the frequency and dissipation parameter. A Fn solution $(50 \mu \mathrm{g} / \mathrm{mL})$ is then introduced for $30 \mathrm{~min}$. Protein deposition is followed during three successive buffer rinses of $5 \mathrm{~min}$ each. Fn coated sensors are subsequently coated with Alb (1\% w/v) solution for an additional $30 \mathrm{~min}$, and then rinsed three times for $5 \mathrm{~min}$ each in PBS. Surface densities as small as $10 \mathrm{ng} / \mathrm{cm}^{2}$ can be precisely determined via QCM-D.

\section{Cell culture}

MC3T3-E1 cells, established as a preosteoblastic cell line from newborn mouse calvaria, ${ }^{25}$ are grown in alpha minimal medium $\left(\mathrm{GIBCO}^{\circledR}\right.$, Invitrogen, Carlsbad, CA) supplemented with $10 \%(\mathrm{v} / \mathrm{v})$ fetal bovine serum (PAA Laboratories, Austria) and $1 \%(\mathrm{v} / \mathrm{v})$ penicillin/streptomycin $(10000 \mathrm{U} / \mathrm{mL}$ and $10000 \mu \mathrm{g} / \mathrm{mL}$, respectively; GIBCO, Invitrogen, Carlsbad, CA). Cells are cultured in $25 \mathrm{~cm}^{2}$ plastic culture flasks and incubated in a humidified incubator at $37^{\circ} \mathrm{C}$ with $5 \% \mathrm{CO}_{2}$.

\section{Immunostaining procedure}

We employ the following antibodies or reagents: mouse monoclonalti-vinculin (1:100; Sigma-Aldrich, Saint Louis, $\mathrm{MO}$, clone hVIN-1), tetramethyl rhodamine iso-thiocyanate (TRITC)-coupled phalloidin (1:400; Sigma-Aldrich, Saint Louis, MO) or fluorescein isothiocyanate-coupled phalloidin (1:200; Sigma-Aldrich, Saint Louis, MO). Goat anti-mouse coupled to TRITC (1:100) was from Sigma-Aldrich (Saint Louis, MO). Nuclei were revealed with $0.1 \mathrm{mg} \mathrm{ml}-1$ 4',6-diamidino-2-phenylindole dihydrochloride (DAPI; SigmaAldrich, Saint Louis, MO).

Cells are fixed in 4\% paraformaldehyde/PBS1X and permeabilized in $0.1 \%$ TritonX-100/PBS for $10 \mathrm{~min}$ at room temperature. A blocking solution consisting of a $0.3 \% \mathrm{w} / \mathrm{v}$ bovine serum albumin diluted in PBS1X is applied for $1 \mathrm{~h}$ at room temperature. Cells are then incubated for $1 \mathrm{~h}$ with primary antibodies, washed three times in PBS1X, and incubated for additional 45 min with secondary antibodies. Finally, coverslips are washed and mounted in Mowiol or PBS-glycerol $(50: 50 \mathrm{v} / \mathrm{v})$. Epifluorescence images were obtained on a microscope (DMLB, Leica, Solms, Germany) equipped with $10 \times$ and $20 \times$ objective lenses, and are recorded on a CCD 
camera (DFC420, Leica, Solms, Germany) using Leica software. Gray level images are treated and assembled using Adobe $^{\circledR}$, Photoshop ${ }^{\circledR}$, and Adobe ${ }^{\circledR}$ Illustrator $^{\circledR}$ CS2 software version 9.0 (Adobe System, Inc.).

\section{E. Cell morphology}

To study individual cell morphology, MC3T3-E1 cells are cultured at an average density of 20000 cells per $\mathrm{cm}^{2}$ during $3 \mathrm{~h}$ in complete medium on the different substrates and coatings. Quantifications are performed using ImageJ software (Rasband, W.S., ImageJ, U.S. National Institutes of Health, Bethesda, Maryland, USA, http://rsb.info.nih.gov/ij/, 1997-2005).

Cell surface: Average cell surface is measured after binarization and thresholding of actin fluorescence gray level acquisitions using the Image J software.

Cell shape: Average cell circularity $[$ Circularity $=$ $4 \pi$ area $\left./(\text { perimeter })^{2}\right]$ and roundness (Roundness $=[$ minor axis]/[major axis]) are measured using ImageJ software based on actin staining. A circularity value of 1 indicates a perfect circle. A value near 0 would most often correspond to a very elongated shape or a stellate morphology with thin membrane protrusions. A roundness value of 1 also corresponds to a perfect circle, whereas a value near 0 indicates a very elongated shape.

\section{F. Statistical analysis}

Statistical analysis was performed using GraphPad Prism 5.0. All data are presented as the mean \pm SEM. One-way repeated measures analysis of variance (ANOVA) is followed by the Dunnett's multiple comparison post-hoc test for the three different substrates independently. A $p<0.05$ is considered as statistically significant.

\section{RESULTS}

\section{A. Surface characterization}

To assess the predominant hydrophobic/hydrophilic nature of the surface, static water contact angles (SWCA) are measured on the different substrates (Fig. 1). As expected, the glass substrate (SO) is highly wettable and present a less hydrophobic surface, with a SWCA of $23^{\circ} \pm 2$ [Figs. 1(a) and $1(\mathrm{~d})]$, whereas PS is the most hydrophobic, presenting a SWCA of $98.5^{\circ} \pm 1.2$ [Figs. 1(c) and 1(d)]. Hydroxyapatite (HA) shows an intermediate hydrophobicity, revealing a SWCA of $69.5^{\circ} \pm 5.6$ [Figs. 1(b) and 1(d)]. To investigate substrate roughness, sensors are tilted forward and backward, and the dynamic contact angle was measured. Deformation of the water drop is most prominent in the case of HA, whereas deformation is very slight for PS, suggesting the important roughness of HA compared to PS. AFM analysis confirms these observations, revealing that HA to be highly rough compared to SO and PS.

\section{B. Surface protein deposition}

QCM-D is used to determine the kinetics of adsorption and the stability of Fn and Fn/Alb layers on the different substrates. In Fig. 2, we show kinetic curves representing Fn and Alb adsorption in series on SO (A), PS (B) and HA (C) surfaces. The substrates are first exposed to Fn for $30 \mathrm{~min}$, and then subjected to three buffer rinses of five min each. Next, Alb is introduced for an additional $30 \mathrm{~min}$, followed again by three 5-min buffer rinses. Adsorption is evident by a decrease in the quartz crystal resonance frequency, and in increase in the dissipation factor. The corresponding mass densities was calculated with the Sauerbrey equation using

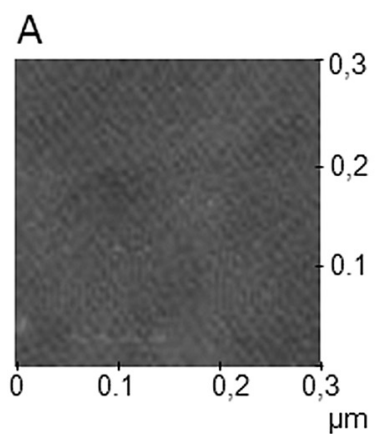

B
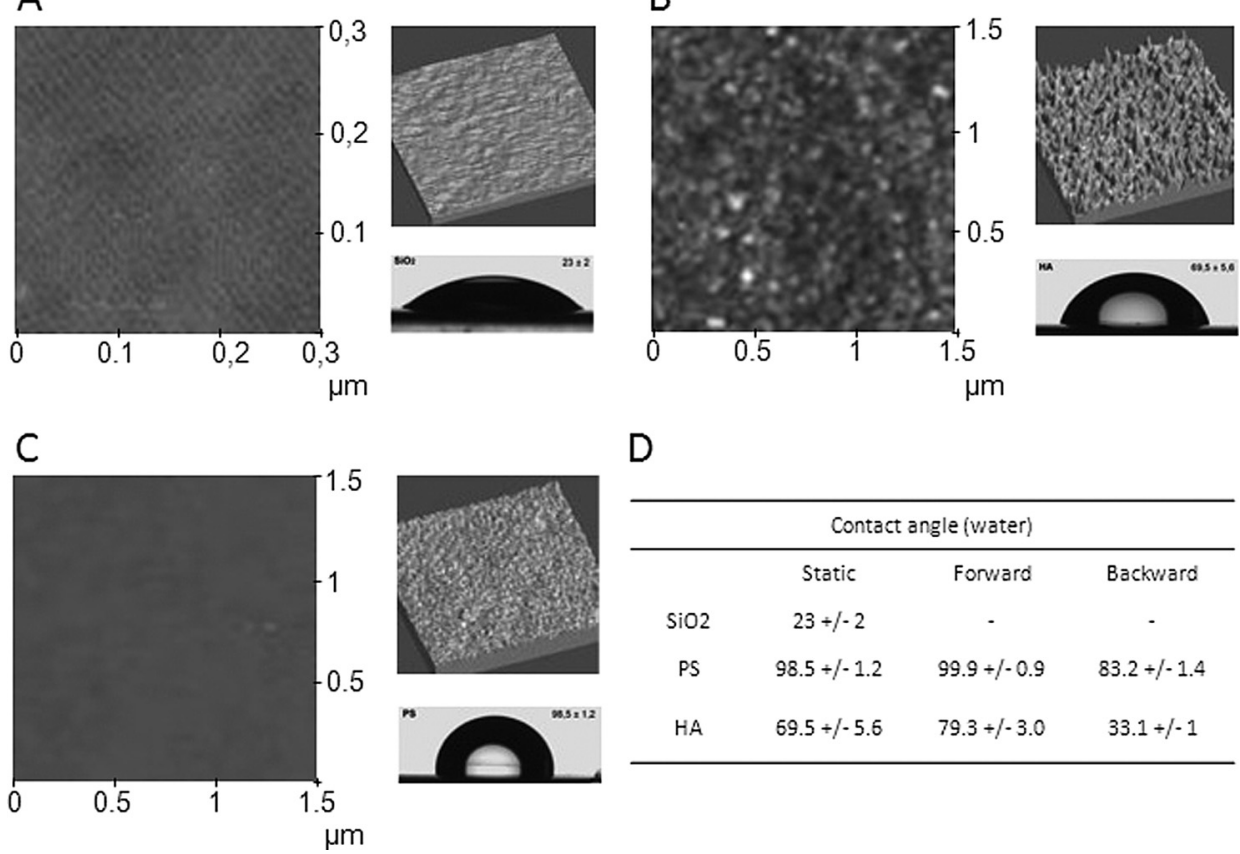

D

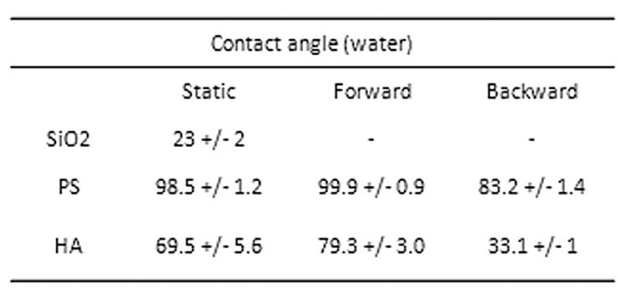

FIG. 1. AFM images and static contact angle photographs on SO (a), PS (b), and HA (c) substrates. Contact angle values (D) using $20 \mu$ l pure deionized water. 
$\Delta \mathrm{m}=-\mathrm{C} \times \Delta \mathrm{fn}$, where $\mathrm{C}$ is a constant equal to $17.7 \mathrm{ng}$ $\mathrm{Hz}^{-1} \mathrm{~cm}^{-2}$. Figure 3(a) Fn adsorption is observed to be very rapid on $\mathrm{SO}$ and $\mathrm{HA}$ (90\% saturation reached at $5 \mathrm{~min}$ ) and somewhat slower on PS (90\% saturation reached at $15 \mathrm{~min}$ ). Following 30 min of adsorption, the Fn quantity is quite similar on each of the three substrates (around $440 \mathrm{ng}+/-$ $40 \mathrm{ng}$ ). During the subsequent buffer rinsing steps, very little Fn desorption occurs on the PS surface, while the Fn density decreases by about $20 \%$ and $50 \%$, respectively, on the SO and HA surfaces.
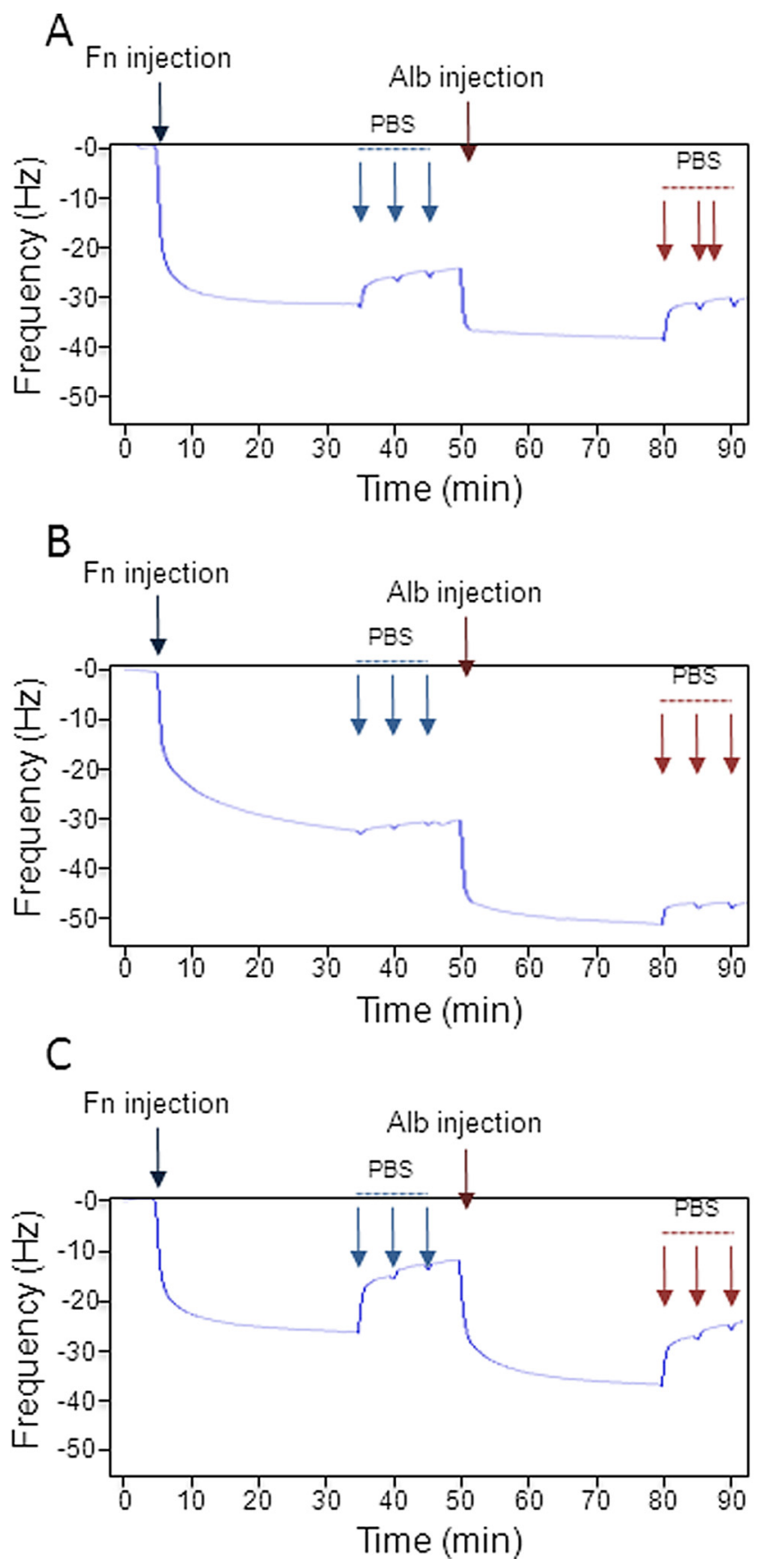

At the 50 min time point, the Fn layer is exposed to an Alb solution, and further adsorption is observed. The extent of additional adsorption is quite different on the three surfaces: 380 on PS, 330 on HA, and 160 on SO (all in $\mathrm{ng} / \mathrm{cm}^{2}$, with uncertainty $+/-40 \mathrm{ng} / \mathrm{cm}^{2}$ ) The second step adsorption to PS is quite stable, with only about $5 \%$ of total protein desorbing during the rinse steps. The SO and HA systems are somewhat less stable, with about $20 \%$ and $35 \%$ of the previously place protein, respectively, desorbing during the second step rinse. In the SO system, this desorption,
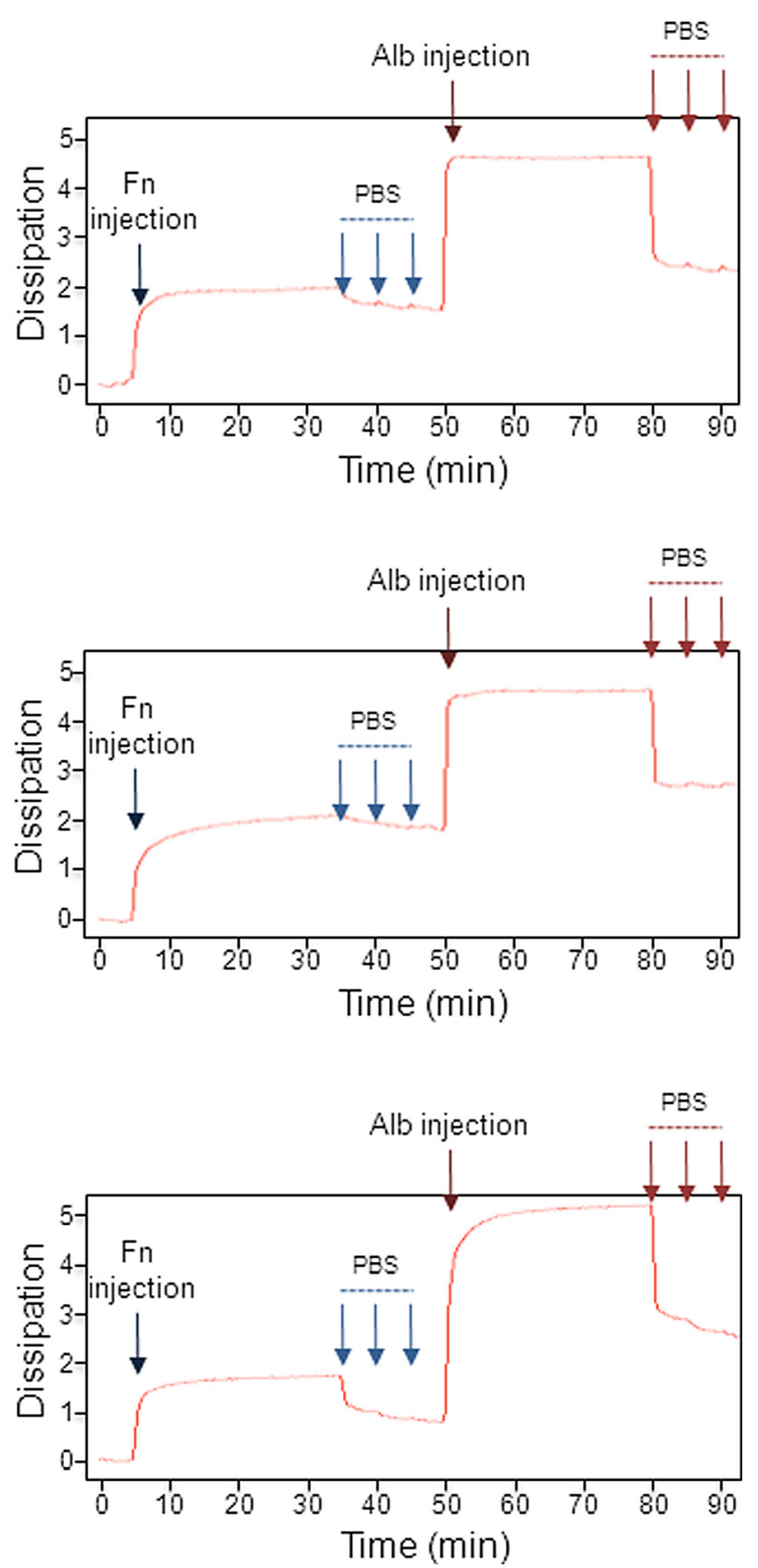

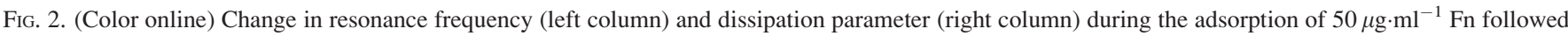
by $1 \%$ Alb adsorption on (a) the SO surface, (b) the PS surface, and (c) the HA surface. F5/5 and the D5/5 frequency and dissipation are shown, of one experiment among a minimum of 3 . 

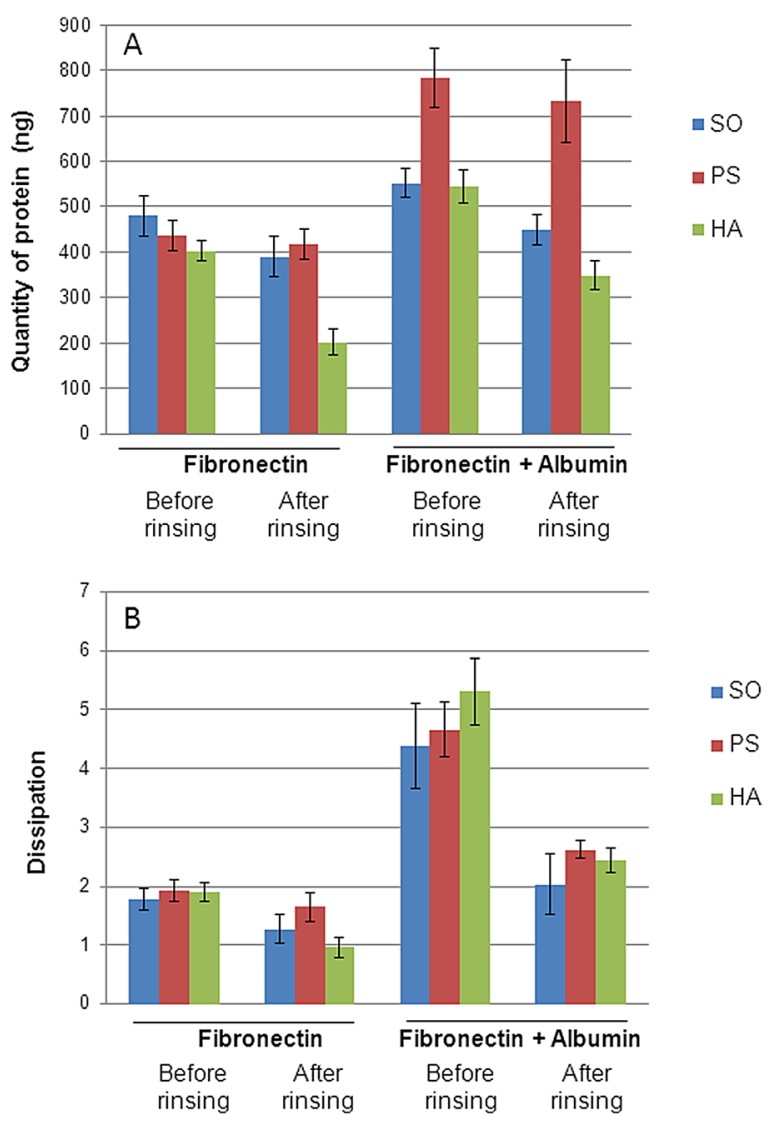

FIG. 3. (Color online) Quantity of protein (a) and change in dissipation parameter (b) during the adsorption of $50 \mu \mathrm{g} \cdot \mathrm{ml}^{-1}$ Fn followed by $1 \% \mathrm{Alb}$ adsorption on the SO surface, the PS surface and the HA surface. The result shown corresponds to the average data of F1, F3, and F5 frequency and D1, D3, and D5 dissipations values of experiments done in triplicate.

combined with the low second step adsorption, results in final quantity of protein that is only $10 \%$ more than that obtained through the first step adsorption + rinse. Assuming no Fn desorption occurs during the second step adsorption or rinse, the layer compositions are $87 \%, 56 \%$, and $57 \%$ Fn on SO, PS, and HA, respectively.

The dissipation parameter, a quantity related to the viscoelastic property of the adlayer, is also investigated at each step and on each substrate [Fig. 3(b)]. Interestingly, whereas the quantity of Fn adsorbed on SO and PS, after rinsing, is about two times larger than that on HA, the dissipation factor of the Fn layer is clearly not two times larger on SO and PS compared to that on HA, suggesting the Fn layer on HA to be softer. Again using dissipation per adsorbed mass as a measure of softness, following addition of the Alb layer, we observe layer softness to rank $\mathrm{HA}>\mathrm{SO}>\mathrm{PS}$.

\section{MC3T3 cell morphology}

In order to test the effects of surface type and protein layer on osteoblastic cell responses in term of attachment and spreading, we consider the morphologies of MC3T3-E1 cells cultured on the various systems. Without any protein layer, cells present different morphologies depending on the material used, as revealed using phalloïdin staining. On SO and HA, cells adhere and present comparable spread morphologies [Figs. 4(a) and 4(c)]. On HA, membrane protrusions can be observed, although cells do not have a clear stellate morphology [Fig. 4(c)]. However, on these two substrates, the average cell surface is quite comparable (around $3800 \mu \mathrm{m}^{2}$, Fig. 5). On PS, MC3T3 surface area is significantly lower (around $1200 \mu \mathrm{m}^{2}$, Fig. 5), and many cells exhibit membrane protrusions [Fig. 4(b)].

On SO, the effect of Fn coating onto the cell spreading is not significant [Figs. 4(d) and 5]. However, many cells present large stress fibers oriented in parallel with one another [Fig. 4(d)]. On PS and HA [Figs. 4(e), 4(f), and 5], the presence of Fn increases significantly the average cell area, to about $5500 \mu \mathrm{m}^{2}$. In the case of PS, this represents a factor 3 increase.

For all substrates cell spreading is promoted to a lesser degree with the Fn + Alb layers than Fn alone does. In the case of SO, the Fn + Alb layer actually induces less spreading than does the bare substrate. On PS and on HA, clear differences are observed in the resulting cell morphologies with and without Alb. On PS, cells exhibit an elongated and bipolar morphology [Fig. 4(h)]. On HA, differences are more subtle and involve the formation of parallel membrane protrusions [Fig. 4(i)].

To further evaluate cell morphology, we consider two additional parameters: cell circularity and cell roundness (see Sec. II). On SO and PS, cell circularity is lower on a Fn coated versus a pure substrate, and lower still for a Fn/Alb coating, with low circularity resulting from a more stellate or elongated morphology [Fig. 6(a)]. On HA, the circularity is about the same on the bare substrate and the Fn layer, but much lower on the Fn + Alb coating. Cell roundness results follow approximately the same trends.

\section{D. МС3T3 focal adhesion organization}

Numerous focal adhesion complexes are observed in MC3T3-E1 preosteoblasts cultured on HA, for all coatings. Cell cytoskeleta appear oriented with large focal adhesion plaques ( $>3 \mu \mathrm{m}$ long) following stress fibers. In particular, on $\mathrm{Fn}+\mathrm{Alb}$ coated HA, cells display oriented protrusions and focal adhesions, and are often polarized following a main axis of the cells, suggesting the cytoskeleton to be sensitive to the nature of the Fn coating. It is interesting to note focal contacts organized around the nucleus to be present only on preosteoblasts cultured on Fn coated HA (i.e., w/o Alb). Furthermore, basal stress fibers perpendicularly oriented to the main axis are also present along cell nucleus (Fig. 7).

\section{DISCUSSION}

The sequential adsorption of two important proteins-Fn and $\mathrm{Alb}$ - on substrates representing a range of physical and chemical properties (e.g., wettability and roughness) is investigated, as well as their resulting effects on MC3T3-E1 early stage behavior. Fn is a key protein of the extracellular matrix, widely used to facilitate cell adhesion, while Alb 


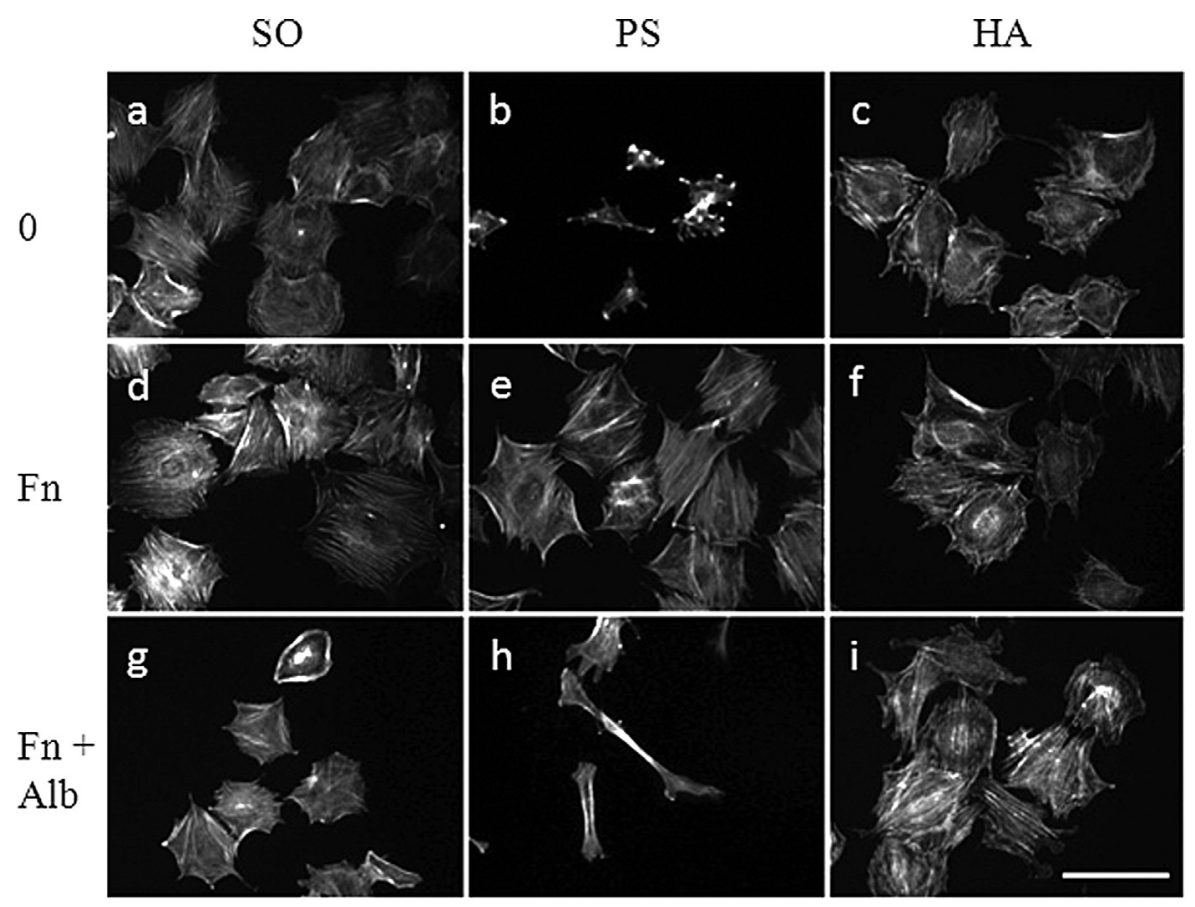

FIG. 4. Morphology of MC3T3 cells depends on substrate type and coating conditions. Actin staining of MC3T3 cells cultured during $3 \mathrm{~h}$ in complete medium on glass (SO), PS, or HA coverslips. Cells are seeded at a density of 20000 cells per $\mathrm{cm}^{2}$ in absence of coating (Ø), with Fn or fibronectin and albumin $(\mathrm{Fn}+\mathrm{Alb})$. The scale bar represents $100 \mu \mathrm{m}$.

generally inhibits cell attachment. ${ }^{33}$ Previous studies have demonstrated how physical and chemical properties of a substrate surface, such as wettability and topography, influence protein adsorption. ${ }^{34,35}$

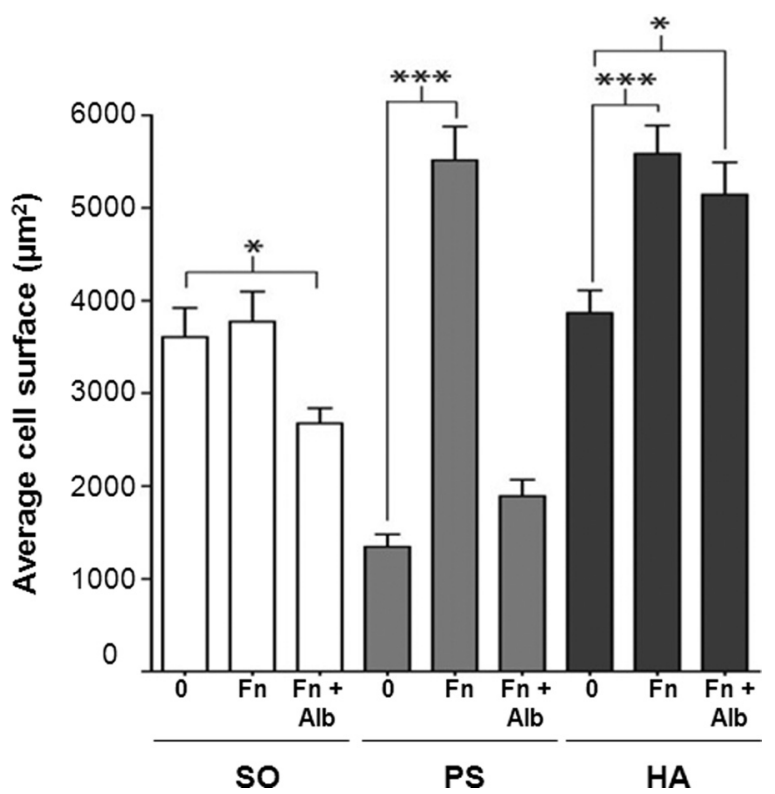

FIG. 5. Quantification of average cell surface area. Average cell surface area is measured using ImageJ software based on actin staining of MC3T3 cells cultured during $3 \mathrm{~h}$ in complete medium on the different substrates and coatings. Statistical analysis is performed using GraphPad Prism 5.0. All data are presented as the mean \pm SEM. One way ANOVA is followed by Dunnett's multiple comparison post-hoc test for the three different substrates independently. A $p<0.05$ is considered to be statistically significant. $(* * * p<0.001 ; * * p<0.01$; and $* p<0.05)$.
The substrates investigated here all have significantly different chemical and physical properties. SO is a metal oxide and quite hydrophilic, PS is an aromatic polymer and quite hydrophobic, and HA is a mineral form of apatite and

Circularity $=4 \pi$ area/[perimeter $]^{2} \quad$ Roundness $=$ [minor axis] $/[$ major axis $]$
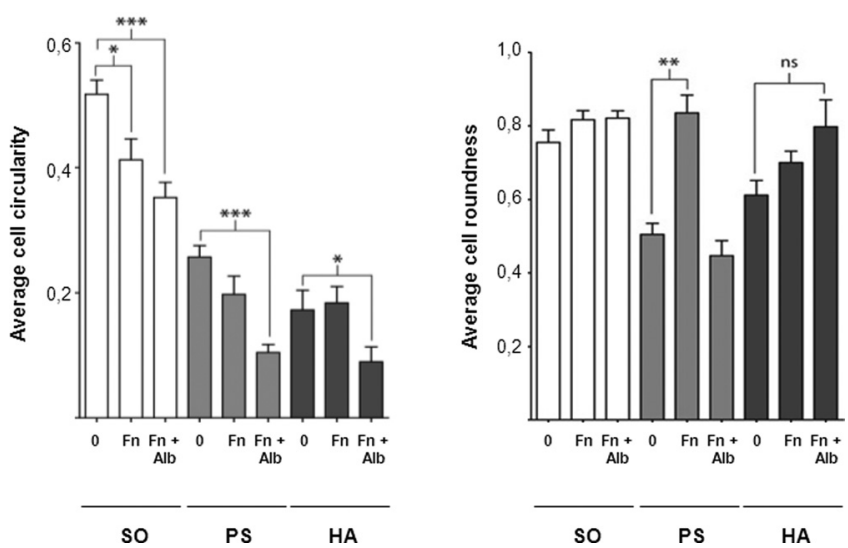

FIG. 6. Evaluation of cell shape through cell circularity and roundness. Average cell circularity and roundness are measured using ImageJ software based on actin staining of MC3T3 cells cultured during $3 \mathrm{~h}$ in complete medium on the different substrates and coatings. A circularity value of 1 indicates a perfect circle. A value near 0 would most often correspond to a very elongated shape or a stellate morphology with thin membrane protrusions. A roundness value of 1 also corresponds to a perfect circle whereas a value near 0 indicates a very elongated shape. Statistical analysis is performed using GraphPad Prism 5.0. All data are presented as the mean \pm SEM. One way ANOVA is followed by Dunnett's multiple comparison post-hoc test for the three different substrates independently. A $p<0.05$ is considered to be statistically significant. $(* * * p<0.001 ; * * p<0.01 ; * p<0.05$; and $\mathrm{ns}=$ nonsignificant). 


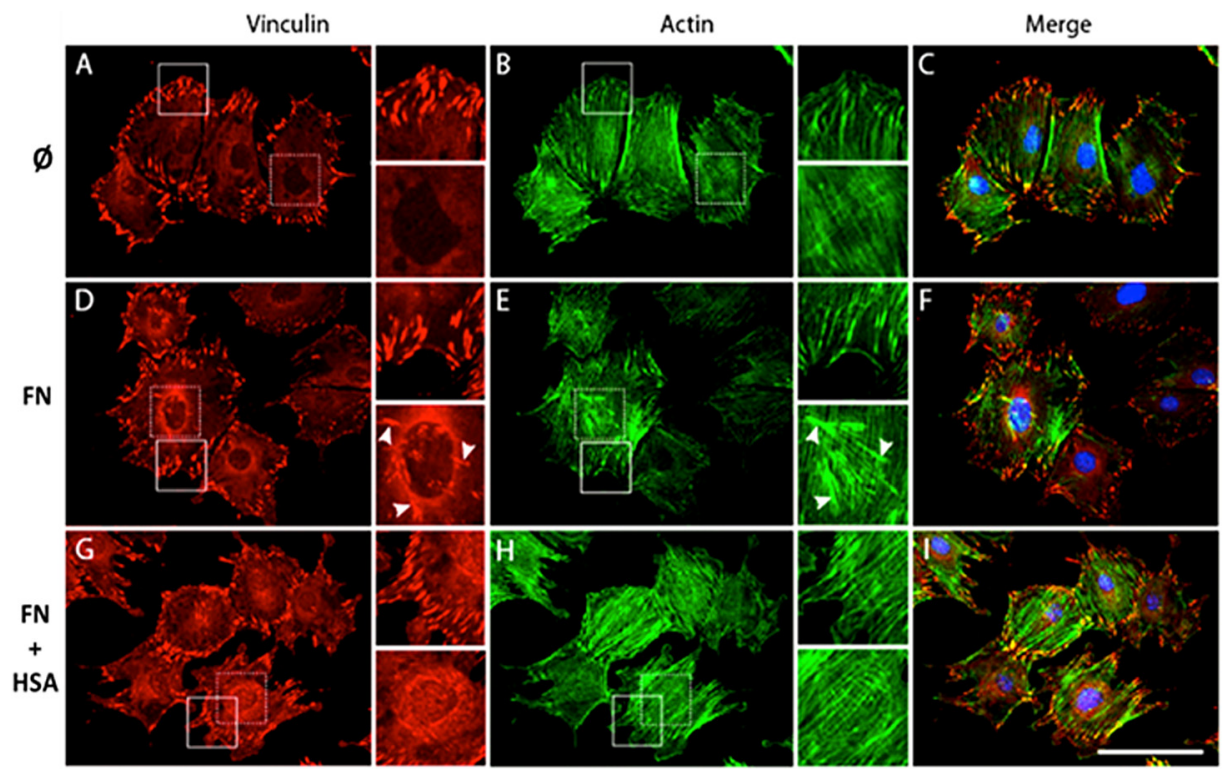

FIG. 7. (Color online) Modification of MC3T3 morphology and focal adhesions organization on hydroxyapatite substrate for various coating conditions. Vinculin (red), actin (green), and nucleus (DAPI; blue) stainings of MC3T3 cells cultured during $3 \mathrm{~h}$ in complete medium on HA. Cells are seeded at a density of 20000 cells per $\mathrm{cm}^{2}$ in the absence of coating $(\mathrm{HA})$, with fibronectin $(\mathrm{HA}+\mathrm{Fn}$ ) or fibronectin and albumin (Fn + Alb) coatings. Scale bar $=100 \mu \mathrm{m}$.

somewhat less hydrophobic than PS. Both SO and PS substrates are quite smooth, whereas HA is rougher on the nanoscale, as demonstrated by liquid contact angle analyses and AFM topographic image. Surface microtopography is known to influence Fn adsorption, but the improved Fn adsorption by nanoscale topography has also been noted. $^{36,37}$ Furthermore, substrate wettability is known to impact Fn adsorption and conformation.

Using QCM-D, we observe the quantity of Fn adsorbed to rapidly reach about $500 \mathrm{ng} / \mathrm{cm}^{2}$ for each substrate studied. The kinetics of adsorption, however, are much slower on the more hydrophobic surface. PS is known to induced a significant denaturation of $\mathrm{Fn}^{35}$ these structural molecular rearrangements may explain the slow kinetics. A significant desorption is observed on HA, compared with SO and PS, and after rinsing and equilibration, the quantity of Fn is two times less on HA then on the other surfaces. According to the size and interfacial organization of Fn, a full monolayer is most likely not reached in the Fn + Alb on HA system.

The QCM-D dissipation parameter represents the ratio of the loss to storage moduli, and generally scales as the film thickness for a given material. The ratio of the dissipation parameter to adsorbed mass is thus a reasonable measure of film "softness" (in a viscoelastic sense). Using this measure, we observe the Fn layers on SO and HA to become softer upon adsorption of Alb, and the Fn layer on PS to become slightly stiffer. As mentioned above, Fn is known to denature on PS; the increased rigidity following Alb adsorption on PS may indicate an aggregation of Alb with the denatured Fn. We also observe the Fn and the Fn + Alb layers on HA to be far softer than the corresponding layers on SO and PS, perhaps indicating weak surface attachment and/or protein conformations mainly in the native state. These results are consistent with those of Renner et al., who investigated Fn displacement at interfaces, and demonstrated a strong correlation of the state of the adsorbed Fn molecules with their exchange characteristic in competition with Alb molecules. ${ }^{38}$ These authors concluded that fibronectin is attached onto hydrophilic surfaces as a "softer," less rigid protein layer, in contrast to the more rigid, densely packed layer on hydrophobic surfaces. As a result, the fibronectin displacement kinetic remains constant for the strongly interacting surface and fibronectin exchange is mainly observed for the weakly interacting surface.

MC3T3-E1 preosteoblasts are cultured for a short period (3h) to investigate the biological influence of the Fn and $\mathrm{Fn}+$ Alb coatings on each of the three substrates. Cell morphology of M3T3-E1 preosteoblasts is significantly modified by the Fn coating even on substrates unfavorable to cell spreading, such as PS. ${ }^{39}$ In all cases, cells spreading is higher and cell circularity is lower when Fn is pre-adsorbed. Also in all cases, a subsequent Alb layer yields lower spreading and lower circularity. In the case of SO and HA, a polygonal cell morphology results, while cells cultured on PS tend to be elongated. Cell spreading is often correlated with amount of Fn present and with substrate stiffness. ${ }^{40}$ Our results tend not to follow this pattern, in particular, the HA substrate contains the least amount of Fn and is the softest (both prior to and after Alb adsorption), yet exhibits the highest degree of cell spreading.

Interestingly, the addition of Alb to the Fn layer has a much greater influence on cells cultured on PS than on cells cultured on SO and HA. The increased rigidity of the $\mathrm{Fn}+\mathrm{Alb}$ layer, and its high stability to a buffer rinse, may indicate Alb aggregation with the Fn layer, possibly acting to block access to the Fn cell binding sites. Previous reports have concluded that coadsorbed Alb can enhance the Fn effect; ${ }^{41}$ our cell spreading results do not corroborate these 

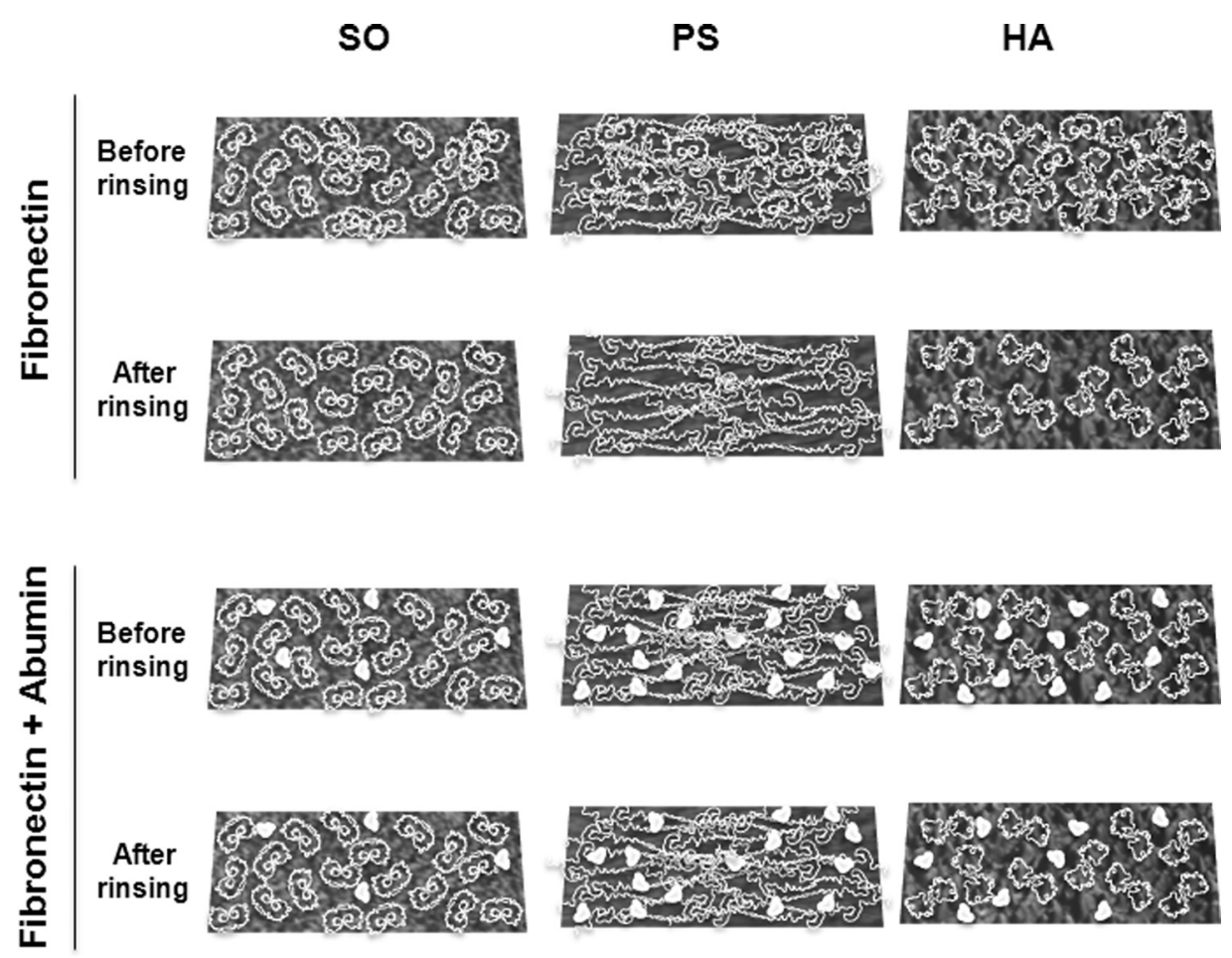

FIG. 8. Schematic representation of structural arrangement and molecular organisation of Fn and Alb on SO, PS, and HA substrates.

findings, although we do note an enhanced influence of cell circularity in each system studied.

To examine HA influence on MC3T3-E1 cells morphology and cytoskeleton organization was visualized. F-actin fibers and focal adhesion contacts were stained on cells cultured on HA after Fn and Alb coating. Cell morphology was sensitively the same on HA whatever the coating was, cell roundness was not significantly different, but Fn coating enhanced cell area. Previous studies demonstrated that Fn was partially unfolded on HA and Fn cell binding domain was more available ${ }^{42}$ whereas Fn bind on a more compact and rigid conformation on gold substrates presenting wettability and stiffness comparable to $\mathrm{SO}{ }^{43}$ Those results may be correlated with the numerous focal contact points observed on HA coated with Fn. The interesting point to focus on was the organization of focal contacts; dorsal adhesion with basal actin fibers was observed only for preosteoblasts cultured on Fn while only conventional focal adhesion was shown on uncoated or Fn + Alb coated HA. Kim et al. demonstrated that such a cell organization was observed on cells cultured on stiff substrate to reduce the squeeze onto the nucleus induced by stress fibers. ${ }^{44}$ Since Fn films are stiffer without the addition of Alb, we hypothesized that the dorsal focal adhesion observed was present to reduce the stress onto the nucleus due to Fn film and subsequently by actin cytoskeleton. Furthermore, HA is the substrate that stimulates the more MC3T3-E1 spreading and the cytoskeleton organization whatever the coating was. In a previous study, nanotopography created by pits $(<10 \mathrm{~nm})$ formed on the surface of poly(L-lactic acid) substrate did not influence MC3T3-E1 cells substrates behavior after a Fn coating. ${ }^{45}$
This topography was hidden by adsorbed Fn film on the substrate. On the contrary, in our study, substrates roughness influenced probably more preosteoblasts behavior than the sequential adsorption of Fn and Alb. Interestingly MC3T3E1 cells cultured on HA coated with Fn had the most numerous focal contacts with a complex cytoskeleton organization and they were the more spread compared to all samples. We hypothesized that HA and Fn had a synergic effect on preosteoblasts adhesion and spreading, and hence, they may influence their functional orientations (e.g., proliferation and differentiation)

\section{CONCLUSION}

We investigate here the adsorption of the matrix protein Fn and the blood protein Alb, and the adhesion and morphology of contacting MC3T3-E1 preosteoblasts, to three important biomaterial surfaces: SO, PS, and HA. We find, as schematized in Fig. 8, Fn adsorption extent, Fn + Alb coadsorption extent, and rigidity of the Alb-Fn layer to rank PS $>$ SO $>$ HA. Despite the weak Fn adsorption and soft protein layer, HA exhibited the highest extent of cell spreading, suggesting it to be especially promising in bone contacting biomaterial applications. We observe no synergy between Fn and Alb; notably, Alb completely reverse the Fn effect in the case of PS, probably due to aggregation with denatured Fn.

${ }^{1}$ C. J. Wilson, R. E. Clegg, D. I. Leavesley, and M. J. Pearcy, Tissue Eng. 11, 1 (2005)

${ }^{2}$ T. O. Collier, C. R. Jenney, K. M. DeFife, and J. M. Anderson, Biomed. Sci. Instrum. 33, 178 (1997). 
${ }^{3}$ J. E. Raynor, J. R. Capadona, D. M. Collard, T. A. Petrie, and A. J. Garcia, Biointerphases 4, 3 (2009).

${ }^{4}$ G. Raffaini and F. Ganazzoli, Macromol. Biosci. 7, 552 (2007).

${ }^{5}$ P. Kingshott, G. Andersson, S. L. McArthur, and H. J. Griesser, Curr. Opin. Chem. Biol. 15, 667 (2011).

${ }^{6}$ F. Grinnell and M. K. Feld, J. Biomed. Mater. Res. 15, 363-381 (1981).

${ }^{7}$ D. K. Pettit, T. A. Horbett, and A. S. Hoffman, J. Biomed. Mater. Res. 26, 1259 (1992).

${ }^{8}$ D. J. Iuliano, S. S. Saavedra, and G. A. Truskey, J. Biomed. Mater. Res. 27, 1103 (1993).

${ }^{9}$ A. J. Garcia, M. D. Vega, and D. Boettiger, Mol. Biol. Cell 10, 785 (1999).

${ }^{10}$ S. Patel, A. F. Chaffotte, F. Goubard, and E. Pauthe, Biochemistry 43, 1724 (2004).

${ }^{11}$ S. Patel, A. F. Chaffotte, B. Amana, F. Goubard, and E. Pauthe, Int. J. Biochem. Cell Biol. 38, 1547 (2006).

${ }^{12}$ E. Pauthe, J. Pelta, S. Patel, D. Lairez, and F. Goubard, Biochim. Biophys. Acta 1597, 12 (2002).

${ }^{13}$ J. Pelta, H. Berry, G. C. Fadda, E. Pauthe, and D. Lairez, Biochemistry 39, 5146 (2000).

${ }^{14}$ I. Wierzbicka-Patynowski and J. E. Schwarzbauer, J. Cell Sci. 116, 3269 (2003).

${ }^{15}$ J. L. Sechler, S. A. Corbett, M. B. Wenk, and J. E. Schwarzbauer, Morphogen.: Cell. Interact. 857, 143-154 (1998).

${ }^{16}$ M. Larsen, V. V. Artym, J. A. Green, and K. M. Yamada, Curr. Opin. Cell Biol. 18, 463 (2006).

${ }^{17}$ P. Rondeau and E. Bourdon, Biochimie 93, 645 (2011).

${ }^{18}$ G. Weber, Adv. Protein Chem. 29, 1 (1975).

${ }^{19}$ J. Wei et al., Biomed. Mater. 4, 045002 (2009).

${ }^{20}$ M. Zelzer, D. Albutt, M. R. Alexander, and N. A. Russell, Plasma Process. Polym. 9, 149 (2012).

${ }^{21}$ S. R. Sousa, M. Lamghari, P. Sampaio, P. Moradas-Ferreira, and M. A. Barbosa, J. Biomed. Mater. Res. Part A 84A, 281 (2008).

${ }^{22}$ M. Tagaya, T. Ikoma, N. Hanagata, T. Yoshioka, and J. Tanaka, Sci. Technol. Adv. Mater. 12, 034411 (2011).

${ }^{23}$ M. Tagaya, T. Ikoma, T. Takemura, N. Hanagata, T. Yoshioka, and J. Tanaka, Langmuir 27, 7645 (2011).

${ }^{24}$ P. J. Molino, M. J. Higgins, P. C. Innis, R. M. I. Kapsa, and G. G. Wallace, Langmuir 28, 8433 (2012).
${ }^{25}$ D. Wang, K. Christensen, K. Chawla, G. Z. Xiao, P. H. Krebsbach, and R. T. Franceschi, J. Bone Miner. Res. 14, 893 (1999).

${ }^{26}$ J. L. Moreau, M. D. Weir, and H. H. K. Xu, J. Biomed. Mater. Res. Part A 91A, 605 (2009).

${ }^{27}$ M. D. Weir and H. H. K. Xu, J. Biomed. Mater. Res. Part A 94A, 223 (2010).

${ }^{28}$ L. A. Bonsignore, J. R. Anderson, Z. Lee, V. M. Goldberg, and E. M. Greenfield, Bone 52, 93 (2013).

${ }^{29}$ M. Chatzinikolaidou, T. K. Lichtinger, R. T. Mueller, and H. P. Jennissen, Acta Biomaterialia 6, 4405 (2010).

${ }^{30}$ W. J. E. M. Habraken, J. G. C. Wolke, and J. A. Jansen, Adv. Drug Deliv. Rev. 59, 234 (2007).

${ }^{31}$ H. Zhou and J. Lee, Acta Biomater. 7, 2769 (2011).

${ }^{32}$ L. Poulouin, O. Gallet, M. Rouahi, and J. M. Imhoff, Protein Expression Purific. 17, 146 (1999).

${ }^{33}$ A. L. Koenig, V. Gambillara, and D. W. Grainger, J. Biomed. Mater. Res. Part A 64A, 20 (2003).

${ }^{34}$ M. B. Hovgaard, K. Rechendorff, J. Chevallier, M. Foss, and F. Besenbacher, J. Phys. Chem. B 112, 8241 (2008).

${ }^{35}$ L. Baujard-Lamotte, S. Noinville, F. Goubard, P. Marque, and E. Pauthe, Coll. Surf. B 63, 129 (2008).

${ }^{36}$ C. Gonzalez-Garcia, S. R. Sousa, D. Moratal, P. Rico, and M. SalmeronSanchez, Coll. Surf. B 77, 181 (2010).

${ }^{37}$ M. Ventre, F. Causa, and P. A. Netti, J. R. Soc. Interf. 9, 2017 (2012).

${ }^{38}$ L. Renner, T. Pompe, K. Salchert, and C. Werner, Langmuir 21, 4571 (2005).

${ }^{39}$ S. N. Stephansson, B. A. Byers, and A. J. Garcia, Biomaterials 23, 2527 (2002).

${ }^{40}$ C. B. Khatiwala, S. R. Peyton, M. Metzke, and A. J. Putnam, J. Cell. Physiol. 211, 661 (2007).

${ }^{41}$ M. S. Lord, C. Modin, M. Foss, M. Duch, A. Simmons, F. S. Pedersen, and F. Besenbacher, Biomaterials 29, 2581 (2008).

${ }^{42}$ A. Dolatshahi-Pirouz, T. Jensen, M. Foss, J. Chevallier, and F. Besenbacher, Langmuir 25, 2971 (2009).

${ }^{43}$ A. Monkawa, T. Ikoma, S. Yunoki, T. Yoshioka, J. Tanaka, D. Chakarov, and B. Kasemo, Biomaterials 27, 5748 (2006).

${ }^{44}$ D. H. Kim, S. Khatau, Y. Feng, S. Walcott, S. Sun, G. Longmore, and D. Wirtz, Mol. Biol. Cell 22, 555 (2011).

${ }^{45}$ M. Hindie, M. C. Degat, F. Gaudiere, O. Gallet, P. R. Van Tassel, and E. Pauthe, Acta Biomater. 7, 387 (2011). 